\title{
Hedging Using Futures and Options Contracts in the Electricity Market
}

\author{
Filipe Azevedo ${ }^{1}$, Zita A. Vale ${ }^{1}$, António A. Vale ${ }^{2}$ \\ ${ }^{1}$ Polytechnic Institute of Porto / Institute of Engineering \\ Rua Dr. António Bernardino de Almeida, 431 - 4200-072 Porto (Portugal), phone:+351 22 8340500, fax:+351 22 8321159, \\ e-mail: fazevedo@dee.isep.ipp.pt, zav@dee.isep.ipp.pt \\ ${ }^{2}$ Department of Electric and Computer Engineering, University of Porto, Phone: +35122 5081400, fax: +351225081441 , \\ e-mail : avale@fe.up.pt
}

\begin{abstract}
Since the 80 's with the experience of Chile, the electric sector has suffered, in many counties, a process of deregulation and liberalization. In almost of the countries, that process originated the appearance of a Pool where the participants of the market trade the electrical energy on a basis of half-hour or one hour of the next day. However, like the traditional markets, the agents of electricity markets are now exposed to the volatility of market price, so far inexistent in those markets. In some countries, to face that problem and to turn the market more liquid have been introduced derivatives markets - futures and options, to negotiate products with underlying active the electrical energy. In this context, there is a need of decision-support tools that allow those agents to use derivatives markets with the objective of practicing the hedge and simultaneously increase their results. In this paper, we present a decision model that supports producers in the establishment of contracts with the objective to maximize the profit expected utility. The paper presents a group of examples of the use of this decision-support system.
\end{abstract}

\section{Key words}

"Risk Management" "Hedge" "Electricity Markets" "Contracts" "Decision"

\section{Introduction}

The separation between product - energy - and service transport and distribution - is the fundamental characteristic of the recent deregulation of the electric sector. This deregulation, associated to the liberalization on an unbundled system, allows the free competition in sectors of activity traditionally monopolist. Facing the new reality, the participants of electricity markets must deal with new challenges and new risks.

The volatility of electric energy price in spot markets is, among the risks in a liberalized market, the one that poses major concerns to the agents of the electric market and, in particular, to the producers.

To reduce their expose to variations in electricity price in spot markets, producers and others agents who participate in those markets make extensive use of futures and options contracts with the objective to practice the hedge.

Some works were realized with the objective to develop tools that permit a better management of the risk in electricity markets. For example, [1] presents a model for the risk management in the valuation of contracts in electricity markets using the concept of efficient frontier for the representation of the relation profit vs risk, [2] presents a group of strategies for the use of futures contracts in electricity markets with the objective to minimize the risk associated to the volatility of electricity price in the spot market. [3] presents a decision support model based in the Benders decomposition techniques.

Brokers are too exposed to risks from price variation once that they sell energy, to the client's majority, at fixed tariffs, while the energy is bought at Pool prices. However, the risks faces by brokers are substantially superiors to those that producers faces because producers may decide not to produce if they consider Pool price to low, while brokers only could interrupt the energy supply to the consumers when Pool price is to high and if they have interruptible contracts.

\section{Causes for the volatility of energy price}

The fluctuation of Pool energy price is directly dependent of two factors:

- Charge characteristics;

- Producer's characteristics.

The charge characteristics that have more impact in the marginal price of the system are:

- Seasonality - the charge is not constant, changing daily, weekly and even annually;

- Mean Reversion - the demand suffer temporary sudden variations, often associated to extreme changes in weather conditions, sports or social events finishing at the demand level of the lasts days;

- Stochastic growth - the demand growth of electric energy is correlated with the country economy growth, being for that, very difficult to predict her evolution for long periods.

The producer's characteristics that have a major impact in system marginal price are:

- Technology - the technology used in the production of electric energy is the principal responsible factor for the production costs, having for that a fundamental influence in producer's bids; 
- Generators availability - the generators service departure due to damage or due to maintenance programs, could have a high influence in electric energy price;

- Fuel price - all over the world the major part of electric energy are of thermal origin, like oil, natural gas and coal. Variations in fuel prices have a high impact in energy cost and consequently in producers bids;

- Technical restrictions - the technical characteristics of generators as operating costs, minimum running time, minimum shutting time, ramp-rate and mechanical constraints have a high impact in producers bids and consequently on the shape of the supply bid curve;

- Import/Export - producer's participations in various electricity markets could influence their bids and consequently the shape of the supply bid curve.

\section{Derivatives markets in electric sector}

The derivatives markets in electric sector were introduced with the objective to turn the electric market more liquid and to provide a group of tools that permit to the electric energy agents the practice of hedge.

They are very similar to those that exist in traditional markets with the characteristic that negotiate products with underlying active the electric energy. The derivatives markets could be organized or not. The organized markets sell normalized contracts while the not organized markets, designated for OTC (over-the counter) markets, sell contracts not normalized.

\section{A. Forward Contracts}

One forward contract is a bilateral agreement where the two parts agree mutually the characteristics (price, quantity, place and date) of one transaction where the payment and the delivery of the asset only are realized in a future date, being the price pre-established, been so, eliminated the risk associated to the price variation.

This type of contracts are different from futures contracts because exist the clear intention for the physical delivery of the asset and they are normally negotiated in not organized markets (off-exchange).

The realization of a forward contract involve two parts where the seller assume a short position and the buyer a long position and the price established in the contract are designated by delivery price.

Assume that, the spot price per unit of energy in the instant that the contract reaches the maturity is $\mathrm{S}_{\mathrm{T}}$ and the delivery price, per unit of energy, established in the contract is $\mathrm{K}$. The payoff of a long position is equal to

$$
\mathrm{S}_{\mathrm{T}}-\mathrm{K}
$$

This payoff is represented in Fig. 1 and it is a result of the obligation by the seller to sell and the buyer to buy the electrical energy negotiated for the value K.

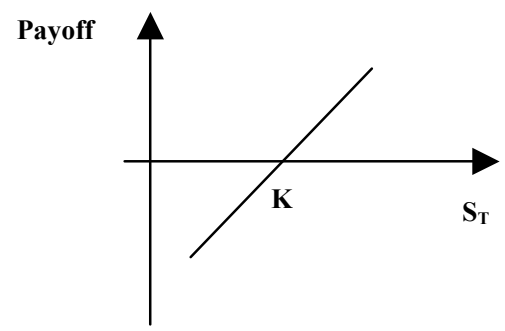

Fig. 1. Payoff at maturity for a long position in a forward contract

The payoff of a short position is represented in Fig. 2 and it is equal to

$$
\mathrm{K}-\mathrm{S}_{\mathrm{T}}
$$

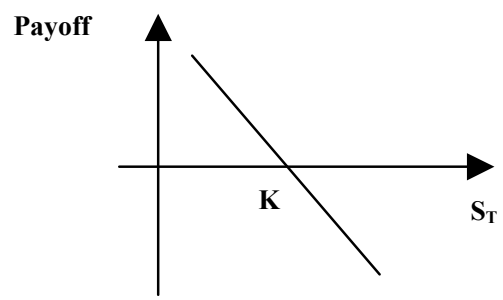

Fig. 2. Payoff at maturity for a short position in a forward contract

Where,

$\mathrm{K}=$ Delivery Price

$\mathrm{S}_{\mathrm{T}}=$ Spot price when the contract rich the maturity

Like in a long position, the payoff of a short position could also assume positive or negative values, as a result of the price in spot market and the obligation by the seller to sell the energy at the value $\mathrm{K}$ (delivery price) stipulated in the contract.

\section{B. Futures Contracts}

Futures contracts are very similar to forward contracts. The characteristics that distinguish them from forward contracts are:

1. Are normalized contracts and negotiated in organized markets, being guaranteed the compliment of the contracts by the Clearing House;

2. The exercise of that type of contracts could be financial, in other words, could not contemplate the 
physical delivery of the energy negotiated in the contract;

3. The Clearing House as a demonstration of good faith requires an initial amount of money - Initial Margin and a maintenance amount - Maintenance Margin along the life of the future contract.

\section{Options Contracts}

Options contracts are contracts that could be established in organized markets or not, giving to his owner, in exchange for a certain monetary quantity (the premium), the right but not the obligation of buy (call option) or sell (put option) a certain quantity of electrical energy, in a predetermined data for a pre-established price.

Exist two types of options, and the factor that distinguishes them is the moment that the options are exercised:

- "American options", could be exercised at any time until the expiration date. These types of options are, however, very expensive due to their versatility;

- "European options", only could be exercised at their expiration date.

In Table I are discriminated the rights and the obligations of the buyer and the seller of call options and put options are discriminated.

TABLE I. - Rights and obligations of buyers and sellers of options

\begin{tabular}{|c|c|c|c|}
\hline Participant & $\begin{array}{c}\text { Obligation } \\
\text { /Right }\end{array}$ & Call & Put \\
\hline \multirow{4}{*}{ Buyer } & Right & $\begin{array}{c}\text { Purchase of } \\
\text { energy at agreed } \\
\text { conditions }\end{array}$ & $\begin{array}{c}\text { Sell of the } \\
\text { energy in the } \\
\text { agreed } \\
\text { conditions }\end{array}$ \\
\cline { 2 - 4 } & Obligation & $\begin{array}{c}\text { Payment of } \\
\text { premium }\end{array}$ & $\begin{array}{c}\text { Payment of } \\
\text { premium }\end{array}$ \\
\hline Seller & Right & $\begin{array}{c}\text { Receive of } \\
\text { premium }\end{array}$ & $\begin{array}{c}\text { Receive of } \\
\text { premium }\end{array}$ \\
\cline { 2 - 4 } & $\begin{array}{c}\text { Obligation } \\
\text { (in case of } \\
\text { exercise) }\end{array}$ & $\begin{array}{c}\text { Sell of the energy } \\
\text { at agreed } \\
\text { conditions }\end{array}$ & $\begin{array}{c}\text { Purchase of } \\
\text { energy in the } \\
\text { agreed } \\
\text { conditions }\end{array}$ \\
\hline
\end{tabular}

The options could have two forms of exercise:

- Monetary delivery: the buyer of the option demand to the seller the delivery of an monetary amount equal to the profit that he have if he buy (call) or sell (put) the energy at the exercise price and then (call) or after (put) sell it (call) or buy it (put) in the spot market.

- Physical delivery: the buyer of the option demand to the seller the delivery of an amount of energy established in the contract at the conditions accorded.

Accordingly to the exercise price and the price of the energy in the spot market, options are grouped in three categories:
- In-the-money - if the exercise price is inferior to the price in the spot market for call options and if the exercise price is superior to the price in the spot market for put options;

- At-the-money - if the exercise price is equal to the price in the spot market;

- Out-the-money - if the exercise price is superior to the price in the spot market for call options and if the exercise price is inferior to the price in the spot market for put options.

\section{Decision Process}

One of the biggest problems that a producer faces when he pretend to practice the hedge is the difficulty that he faces to predict the system marginal price for a certain period $i$ in question.

So, is fundamental the consideration of a group of scenarios for the system marginal price to the period in question and associate to them a certain probability based on statistics studies or based on the opinion of an expert.

The decision process here presented comprise, for a certain programmed period, the determination of optimal quantities of energy to negotiate in "financial markets" and the foresee energy to negotiate in the spot market, in function of previous contracts established, with the objective to maximize the profit expected utility.

The decision process scheme is represented by Fig. 3 .

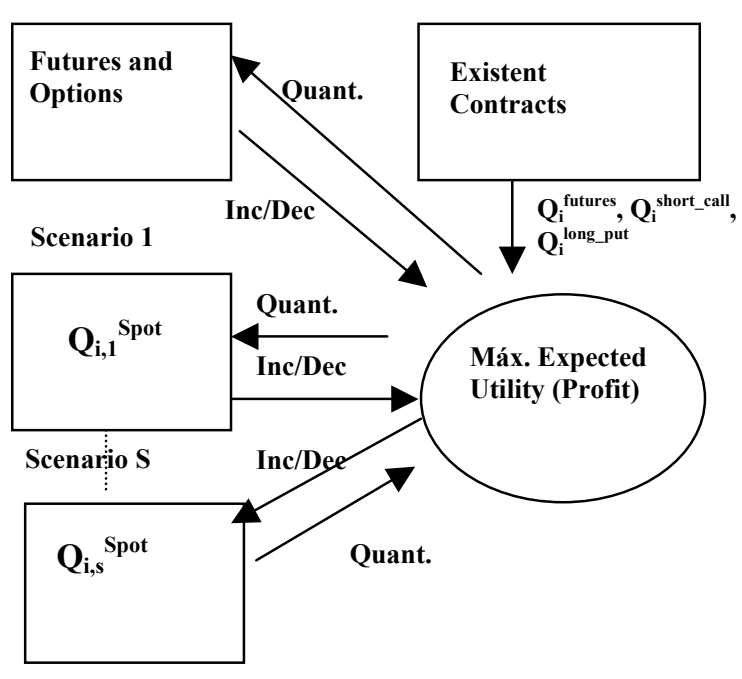

Fig. 3. Decision Model

\section{Mathematical Formulation}

The mathematical model which translates the optimal strategy for the optimal energy quantity to negotiate in forward and options contracts and in the spot market, 
with the objective to maximize the profit expected utility is given by:

$$
\begin{aligned}
& \text { Maximize } \\
& \sum_{i=1}^{S} U\left(v_{i, s, E}^{\text {futures }}+v_{i, s, E}^{\text {short_call }}+v_{i, s, E}^{\text {long_put }}+v_{i, s}^{\text {futures }}+v_{i, s}^{\text {long_call }}+v_{i, s}^{\text {short_put }}+v_{i, s}^{\text {spot }}-\right. \\
& \left.-C\left(Q_{i}^{\text {short_call }}+Q_{i, E}^{\text {short_call }}+Q_{i}^{\text {long_put }}+Q_{i, E}^{\text {long }}{ }^{\text {put }}+Q_{i}^{\text {futures }}+Q_{i, E}^{\text {futtures }}+Q_{i, s}^{\text {spot }}\right)\right) \times p_{i, s}
\end{aligned}
$$

\section{Subjected to:}

$$
\begin{aligned}
& Q_{i}^{\text {short_call }}+Q_{i, E}^{\text {short_call }}+Q_{i}^{\text {long_put }}+Q_{i, E}^{\text {long_put }}+Q_{i}^{\text {futures }}+Q_{i, E}^{\text {futures }}+Q_{i, s}^{\text {spot }} \leq Q^{\text {máx }} \\
& Q_{i}^{\text {shor__call }}+Q_{i, E}^{\text {short_call }}+Q_{i}^{\text {long_put }}+Q_{i, E}^{\text {long_put }}+Q_{i}^{\text {fitures }}+Q_{i, E}^{\text {futures }}+Q_{i, s}^{\text {spot }} \geq Q^{\text {min }} \\
& Q_{i}^{\text {short_call }}, Q_{i, E}^{\text {short_call }}, Q_{i}^{\text {long_put }}, Q_{i, E}^{\text {long_put }}, Q_{i}^{\text {futures }}, Q_{i, E}^{\text {futures }}, Q_{i, s}^{\text {spot }} \in \Re
\end{aligned}
$$

\section{Where,}

- $\quad p_{\text {mis }}$ represent, for the period $i$, the marginal electrical energy price for the scenario s.

- $p_{\text {is }}$ represent, for the period $i$, the probability of occurrence of scenario s.

- $\quad v_{i, s}^{\text {futures }}$ Represent the sells of the existent futures contracts for the supply of a quantity $Q_{i}^{\text {futures }}$, for the period $\mathrm{i}$ and scenario $\mathrm{s}$, at the exercise price $\mathrm{K}_{\mathrm{if}}$. The sells of futures contracts are given by $Q_{i}^{\text {futures }} * K_{i f}$.

- $\quad v_{i, s, E}^{\text {futures }}$ Represent the sells of the existent futures contracts for the supply of a quantity $Q_{i, E}^{\text {futures }}$, for the period $i$ and scenario $s$, at the exercise price $K_{\mathrm{ifE}}$. The sells of existent futures contracts are given by $Q_{i, E}^{\text {futures }} * K_{i f E}$.

- $\quad v_{i, s}^{\text {short_call }}$ Represent the sells that the producer will do if he sell the call option with the quantity $Q_{i}^{\text {short_call }}$ at the exercise price $K_{i}^{\text {short_call }}$ and premium $P_{i}^{\text {short_call }}$, for the period $\mathrm{i}$ and scenario s. The amount of money that the producer will do with the sell of the call option for the period i depends of considered scenarios and of system marginal price, and they are given by:

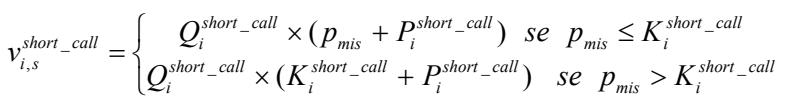

We admit that the buyer of the option call only exercise the option if the price in the spot market will be higher then the exercise price, and the producer are able to sell the energy negotiated in the spot market if the buyer don't exercise the option.
- $\quad v_{i, s, E_{-}}^{\text {short }}$ call Represent the sells that the producer will do with the sell of the existent call option with the quantity $Q_{i, E}^{\text {short_call }}$ at the exercise price $K_{i, E}^{\text {short_call }}$ and premium $P_{i, E}^{\text {short_call }}$ for the period i and scenario s. The amount of money that the producer will do with the sells of the existents call options is determinate in the same way that the call options that the producer wants to negotiate.

- $\quad v_{i, s}^{\text {long_put }}$ Represent the sells that the producer will do if he buy the call option with the quantity $Q_{i}^{\text {long_put }}$ at the exercise price $K_{i}^{\text {long }}{ }^{\text {put }}$ and a premium $P_{i}^{\text {long }}{ }^{\text {put }}$ for the period $\mathrm{i}$ and scenario s.

The sells as a result of the buy option put for the period i, depends from the considerate scenarios for the system marginal price, and they are given by:

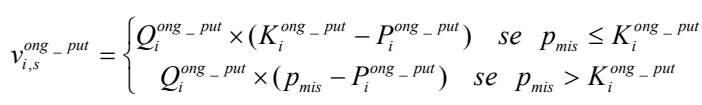

In the put options we also admit that the buyer of the put option only exercise the option if the price in the spot market will be inferior to the exercise price, and the producer are able to sell the energy negotiated in the spot market if the buyer don't exercise the option.

- $\quad v_{i, s, E}^{\text {long }}{ }^{p u t}$ Represent the sells that the producer will do with the buy of the existent put option with the quantity $Q_{i, E}^{\text {long }}{ }^{\text {put }}$ at the exercise price $K_{i, E_{-}}^{\text {long }}$ put and premium $P_{i, E}^{\text {long }{ }_{-} \text {put }}$ for the period $\mathrm{i}$ and scenario s. The amount of money that the producer will do with the sells of the existents put options is determinate in the same way then the put options that the producer wants to negotiate.

- $\quad v_{i, s}^{\text {spot }}$ Represent the sells as a result by the sell of the quantity $Q_{i, s}^{s p o t}$ in the spot market, for the period i and scenario s, and they are given by $Q_{i, s}^{s p o t} \times p_{\text {mis }}$.

- Qmáx represents the maximum active power that the generator can produce.

- Qmin represents the minimum active power that the generator can produce.

- $\mathrm{C}($.) represent the production costs for a active power expressed in MW.

The difficulty to obtain the result of the sells and buys of the call and put options, as well the combinatory character of this problem to obtain the optimal quantity to establish in each contract and to sell in spot market depending on the scenario, turn impossible the resolution of this problem for the traditional methods. 
So, to resolve this problem and to overtake to old problems we use genetic algorithms, particularly the EVOLVER software.

\section{Study Case}

Let us considering an example with the aim to determine the optimal quantity of energy that a producer must negotiate in futures and options contracts and the energy that he should sell in the spot market, for a certain period $i^{1}$. In this example, we consider the scenarios for marginal system price for that period presented in Table II.

TABLE II - System marginal price scenarios for the period i

\begin{tabular}{|l|c|c|}
\hline Price & 22 & 27 \\
\hline Probability & 0.4 & 0.6 \\
\hline
\end{tabular}

The contracts previously established are presented in Table III and IV.

TABLE II - Options contracts previously established

\begin{tabular}{|c|c|c|}
\hline Options & Short call & Long Put \\
\hline $\begin{array}{c}\text { Exercise price } \\
(\mathbf{\epsilon} / \mathbf{M W h})\end{array}$ & 22.00 & 25.00 \\
\hline Premium (€/MWh) & 1.12 & 1.40 \\
\hline $\begin{array}{c}\text { Quantity/Contract } \\
\text { (MWh) }\end{array}$ & 10 & 10 \\
\hline N. ${ }^{\text {of contracts }}$ & 1 & 1 \\
\hline
\end{tabular}

TABLE III - Futures contracts previously established

\begin{tabular}{|c|c|}
\hline Futures & \multicolumn{2}{|c}{} \\
\hline N. ${ }^{\circ}$ of contracts & 0 \\
\hline
\end{tabular}

We admit that futures and options contracts will be established in organized markets with the characteristics are presented in Tables V and VI.

TABLE V - Futures contracts characteristics for period i

\begin{tabular}{|c|c|}
\hline Quantity (MWh) & Delivery Price (€/MWh) \\
\hline 15 & 24.80 \\
\hline
\end{tabular}

\footnotetext{
${ }^{1}$ We consider that the period $i$ has one hour of duration.
}

TABLE IVI - Options contracts characteristics for period i

\begin{tabular}{|c|c|c|c|}
\cline { 2 - 4 } \multicolumn{1}{c|}{} & $\begin{array}{c}\text { Exercise } \\
\text { price } \\
(\boldsymbol{\epsilon} / \mathbf{M W h})\end{array}$ & $\begin{array}{c}\text { Premium } \\
(\boldsymbol{\epsilon} / \mathbf{M W h})\end{array}$ & $\begin{array}{c}\text { Quantity/Contract } \\
\mathbf{( M W h )}\end{array}$ \\
\hline Call & 24.00 & 1.68 & 10 \\
\hline Put & 24.00 & 1.12 & 10 \\
\hline
\end{tabular}

\section{A. Results}

The results for the example considered are presented in Tables VII, VIII and IX.

TABLE VI - Optimal options contracts to realize

\begin{tabular}{|c|c|c|}
\hline Options & Short call & Long Put \\
\hline $\begin{array}{c}\text { Exercise price } \\
(\boldsymbol{\epsilon} / \mathbf{M W h})\end{array}$ & 24.00 & 24.00 \\
\hline Premium (€/MWh) & 1.68 & 1.12 \\
\hline $\begin{array}{c}\text { Quantity/Contract } \\
\text { (MWh) }\end{array}$ & 10 & 10 \\
\hline $\mathbf{N .}^{.}$of contracts & 4 & 0 \\
\hline
\end{tabular}

TABLEVII - Optimal futures contracts to realize

\begin{tabular}{|c|c|}
\hline Futures & \\
\hline $\mathbf{N} .^{\circ}$ of contracts & 0 \\
\hline
\end{tabular}

TABLE IX - Spot energy forecast to sell in spot market for period $\mathrm{i}$

\begin{tabular}{|c|c|}
\hline Spot & \\
\hline Quantity (MWh) & 40 \\
\hline
\end{tabular}

Considering that all contracts have to be established in organized markets, from the results we observe that the electrical energy producer for the period i mustn't sell any forward contract, sell four call options and expect to sell $40 \mathrm{MWh}$ in the spot market.

The producer does not know if the buyer will exercise or not the options that he purchase and has to decide if exercise or not the put option previously negotiated for the same period $\mathrm{i}$.

To decide that, we calculate for all situations of exercise for the options the expected profit for period $i$ and the standard deviation of the profit considering system marginal in the interval $[20 ; 30] € / \mathrm{MWh}$.

Note that, like we consider in the decision model, in all situations that the options weren't exercised, the electrical energy negotiated in those contracts will be 
negotiated in the spot market at the considered marginal price.

The results are presented in Fig. 4 considering the nomenclature presented in Table X.

TABLE X - Designation for the nomenclature used

\begin{tabular}{|l|l|}
\hline Nomenclature & Designation \\
\hline All & All options are exercised \\
\hline Call+Call_E & $\begin{array}{l}\text { Only the new call option and the } \\
\text { previously negotiated call option are } \\
\text { exercised }\end{array}$ \\
\hline Call & Only the new call option is exercised \\
\hline Call+Put_E & $\begin{array}{l}\text { Only the new call option and the } \\
\text { previously negotiated put option are } \\
\text { exercised }\end{array}$ \\
\hline Call_E & $\begin{array}{l}\text { Only the previously negotiated call } \\
\text { option is exercised }\end{array}$ \\
\hline Call_E+Put_E & $\begin{array}{l}\text { Only the previously call option and put } \\
\text { options are exercised }\end{array}$ \\
\hline Put_E & $\begin{array}{l}\text { Only the previously negotiated put } \\
\text { option is exercised }\end{array}$ \\
\hline None & None of the options are exercised \\
\hline
\end{tabular}

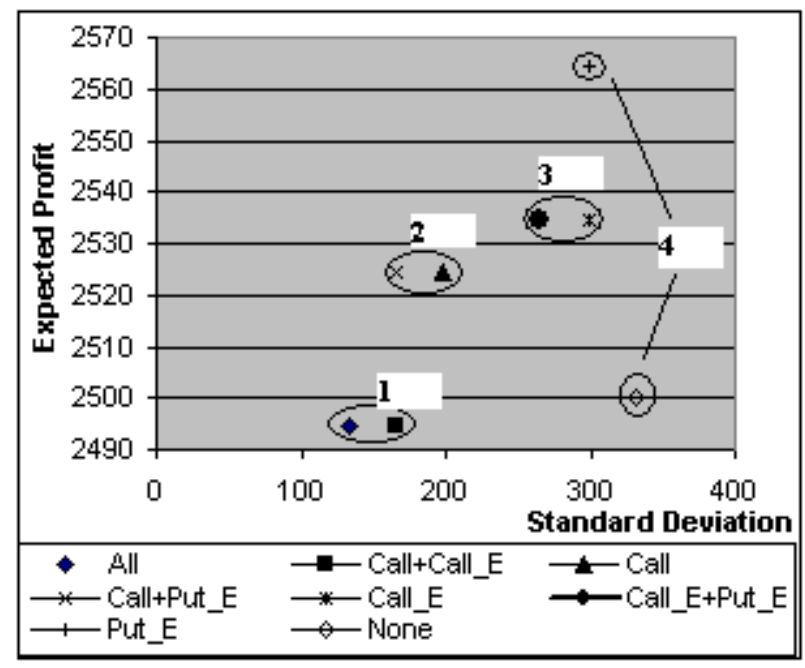

Fig. 4 - Expected profit and profit standard deviation

Through the analysis of the results presented in Fig. 2 it is visible that the producer should, in any situation, exercise the put option previously established, because with this exercise he can reduce the volatility of the profit.

In situations 1, 2 and 3 the exercise of the put option does not increase the expected profit but it reduces de volatility. In situation 4 , the exercise of the put option besides turning the profit bigger, reduces the volatility of the profit.

\section{Conclusion}

Beside the works realized to model the spot energy price, those models are limited and have some difficulties to translate so complex characteristics like the characteristics of the spot market.

The decision support developed in this work, makes extensive use of forward and options contracts to permit to the producers the practice of the hedge against the volatility of the electricity price in the spot market.

Options in this work reveals extremely useful to reduce the volatility of the producer's return and demonstrate that derivatives markets introduce extremely powerful tools for the practice of the hedge and to increase their results.

However, the decision support model developed in this work only looks for the economics aspects. Will be useful interact this decision support model with technical validation. The use of a knowledge base that support the decision based in earlier events will be also extremely useful.

\section{References}

[1] R. Bjorgan, R. Liu, J. Lawarrée, "Financial risk management in a competitive Electricity Market", IEEE Transactions on Power Systems, 2003 (to be published).

[2] E. Tanlapco, J. Lawarrée, "Hedging With Futures Contracts in a Deregulated Electricity Industry", IEEE Transactions on Power Systems, Vol. 17, N. ${ }^{\circ}$ 3, August 2002.

[3] M. V. Pereira et al., "METHODS AND TOOLS FOR CONTRACTS IN A COMPETITIVE FRAMEWORK", Task Force 38.05.09, Cigré, Feb. 2001.

[4] C. W. Richter, G. B. Sheblé, "Bidding Strategies that Minimize Risk with Options and Futures Contracts", American Power Conference, 1998.

[5] A. G. Diaz., P. L. Marin, "Strategic Bidding in Electricity Pools With Short-Lived Bids: An Application to The Spanish Market", CEPR Discussion Paper N. ${ }^{\circ} 2567$, Sept. 2000.

[6] I. Praça, C. Ramos, Z. A. Vale, "Competitive Electricity Markets: Simulation to Improve Decision Making", Porto Power Tech 2001, Sep. 2001. 